\title{
Regional Sea Level Variation on Interannual Timescale in the East China Sea
}

\author{
Shouwen Zhang1,2, Ling Du1 ${ }^{*}$, Hui Wang2, Hua Jiang2 \\ ${ }^{1}$ Department of Oceanography, Ocean University of China, Qingdao, China \\ ${ }^{2}$ National Marine Environmental Forecasting Center, State Oceanic Administration, Beijing, China \\ Email: zhangshouwen@ouc.edu.cn, ${ }^{*}$ duling@ouc.edu.cn, wangh@nmefc.gov.cn, hjiang@nmefc.gov.cn
}

Received 12 September 2014; revised 2 October 2014; accepted 28 October 2014

Copyright (C) 2014 by authors and Scientific Research Publishing Inc.

This work is licensed under the Creative Commons Attribution International License (CC BY).

http://creativecommons.org/licenses/by/4.0/

\section{(c) (7) Open Access}

\begin{abstract}
Interannual sea level variation is investigated with the oceanic and atmospheric datasets in the East China Sea (ECS). Two modes are distinct on the interannual timescale, illustrated as the basin mode and the dipole mode. They account for $20 \%$ and $18 \%$ to the total interannual sea level variance respectively. The basin mode corresponds to the variability of the Kuroshio transport which is modulated by the PDO while the dipole mode is likely related to the local oceanic and atmospheric adjustment. Large-scale atmospheric circulation effect is dominant in influencing the interannual sea level in the ECS. ECS sea level responds barotropically to the basin-wide wind field, which illustrates negative correlation to the zonal-mean wind stress curl in the Pacific Ocean. Sea level variation exhibits the negative correlation at 8 years lag with the basin mean wind stress curl anomalies on the interannual timescale. The lagging years are consistent with the timescale that the baroclinic Rossby waves propagate westward in the North Pacific Ocean. Wind stress curl anomalies could also change the strength of the Kuroshio transport, and thus affect the local sea level through sea surface height adjustment. Local oceanic and atmospheric effect illustrates as another influence process. Steric effect contributes more than $20 \%$ to the interannual sea level gradually in a belt from the Fujian and Zhejiang coasts to the Korea/Tsushima strait. Especially in the northeast part, its contribution could be up to $60 \%$. While for the local atmospheric process, zonal wind acts as a more important role on sea level than meridional component.
\end{abstract}

\section{Keywords}

ECS Sea Level, Interannual Variation, Wind Field, Ocean Current, Steric Effect

\section{Introduction}

Sea level rise will contribute to upward trends in extreme coastal high water levels, so it has drawn wide atten-

"Corresponding author.

How to cite this paper: Zhang, S.W., Du, L., Wang, H. and Jiang, H. (2014) Regional Sea Level Variation on Interannual Timescale in the East China Sea. International Journal of Geosciences, 5, 1405-1414. 
tion by human society, particularly when it affects civil lives (in terms of infrastructure and other elements) within low-lying coastal areas [1]. Yet such a study will never be an easy task as the affecting elements to it differ both spatially and temporally. The magnitude of sea level rise varies geographically, attaining values of up to $10 \mathrm{~mm} / \mathrm{yr}$ in the Pacific warm pool, which is three times of the mean global value [2]; From seasonal to centurial scale, sea level rise can differ dramatically and show multiple regional characteristics.

Differing substantially from the global mean sea level rise, regional sea level variation could be more complicated, as it occurs within the specific dynamic and thermal environment under the atmospheric forcing and ocean circulation. Generally speaking, the regional sea level pattern can be mainly established through windinduce redistribution of upper ocean water [3]-[5]. Through pushing large quantities of water from one location to another, regional ocean currents could cause a massive redistribution of water mass properties, and this would also lead to significant sea level responses [6]. In addition, integral of local density fluctuations, through changes of temperature and salinity within the water column, could also be partly used to interpret the sea level changes.

So far, considerable researches have been focusing on the regional sea level variation and its possible reasons, e.g., the study of sea level changes in the East China Sea (ECS). The ECS is among the broadest shallow shelves and biologically productive seas in the world. It stands as an extremely dynamic region which is forced by the strong East Asian monsoon system. Its sea level changes are subject to the boundary current (Kuroshio) in the east edge, the El Niño-Southern Oscillation (ENSO) and the Pacific Decadal Oscillation (PDO). Ocean thermal and dynamic environments exhibit the temporal and spatial variation in the ECS. By using T/P altimetry data, characteristics of the ECS have been investigated by many scholars [7] [8]. By analyzing the seasonal signal removed sea level data, Yan et al. [9] show the quasi-biennial sea level oscillation is prominent. Zhang et al. [10] confirm that the interannual sea level variation is very significant in the ECS. Besides, they find the interannual sea level varies geographically and temporally. In this case, understanding the thermal and dynamic processes which influence the regional interannualsea level variation becomes the main research spot. Wang et al. [11] mention that the interannual sea level spatial patterns of the principal components correspond to the oceanic currents. Results of Han et al. [12] state that on the interannual and longer-term timescale, steric effect only contributes partially suggesting other factors such as Asia monsoon plays an indispensible role. Large-scale atmospheric circulation could change the strength of the Kuroshio in the ECS [13] and thus influence the sea level by changing the balance of the net water flux. Liu et al., [14] denote that ENSO could influence the local wind field and thus the interannual sea level variation indirectly.

In this paper, satellite altimetry data, together with several available ocean and atmosphere reanalysis products will be used to analyze the sea level variation and its possible mechanisms on interannual timescales in the ECS $\left(22^{\circ} \mathrm{N}-45^{\circ} \mathrm{N}, 116^{\circ} \mathrm{E}-130^{\circ} \mathrm{E}\right.$, western off the Ryukyu Islands chain). Large-scale atmospheric circulation effect and local oceanic-atmospheric adjustment are studied and discussed respectively.

\section{Data and Method}

Sea level anomalies (SLA) data is obtained from the AVISO (Archiving, Validation and Interpretation of Satellite Oceanographic data) Altimetry data center. Various corrections, such as media and instrument corrections (ionosphere delay, dry and wet troposphere, and electromagnetic bias) and geophysical correction (solid Earth, tidal and inverted barometer) are applied to the raw altimeter measurements. It's the most commonly used and accurate observational sea level data at present. Data from 1993 to 2010 is extracted to analyze the interannual variation of the ECS. Prior to using, the raw weekly products with the spatial resolution of $1 / 3^{\circ} \times 1 / 3^{\circ}$ are resampled into monthly data.

To analyze the contribution of wind, steric effect and ocean current on the sea level, we have used the European Centre for Medium-Range Weather Forecasts (ECMWF) Reanalysis datasets (ORA-S3) [15], monthly objectively analyzed subsurface temperature and salinity (version 6.9, [16]) and Simple Ocean Data Assimilation (SODA) datasets. For the ECMWF ORA-S3 datasets, wind stress and sea level data from 1960 to 2009 are used. The ocean current data of two sections along the Kuroshio in ECS [PN section $\left(126^{\circ} \mathrm{E}, 29^{\circ} \mathrm{N}-27.5^{\circ} \mathrm{E}, 128.2^{\circ} \mathrm{E}\right)$ and TW section $\left(121.75^{\circ} \mathrm{E}, 25.25^{\circ} \mathrm{N}-124.25^{\circ} \mathrm{E}, 24.25^{\circ} \mathrm{N}\right.$ )] are from the SODA datasets (shown in Figure $1(\mathrm{a})$ ). PDO index is available from http://jisao.washington.edu/pdo/PDO.latest.

The empirical orthogonal function (EOF) analysis is a suitable tool to give a space-time description of variability. In this paper, it's used to identify dominant modes of interannual sea level. To understand the mechanisms behind the interannual sea level change, correlation analysis method is applied. Correlation analysis method is a 

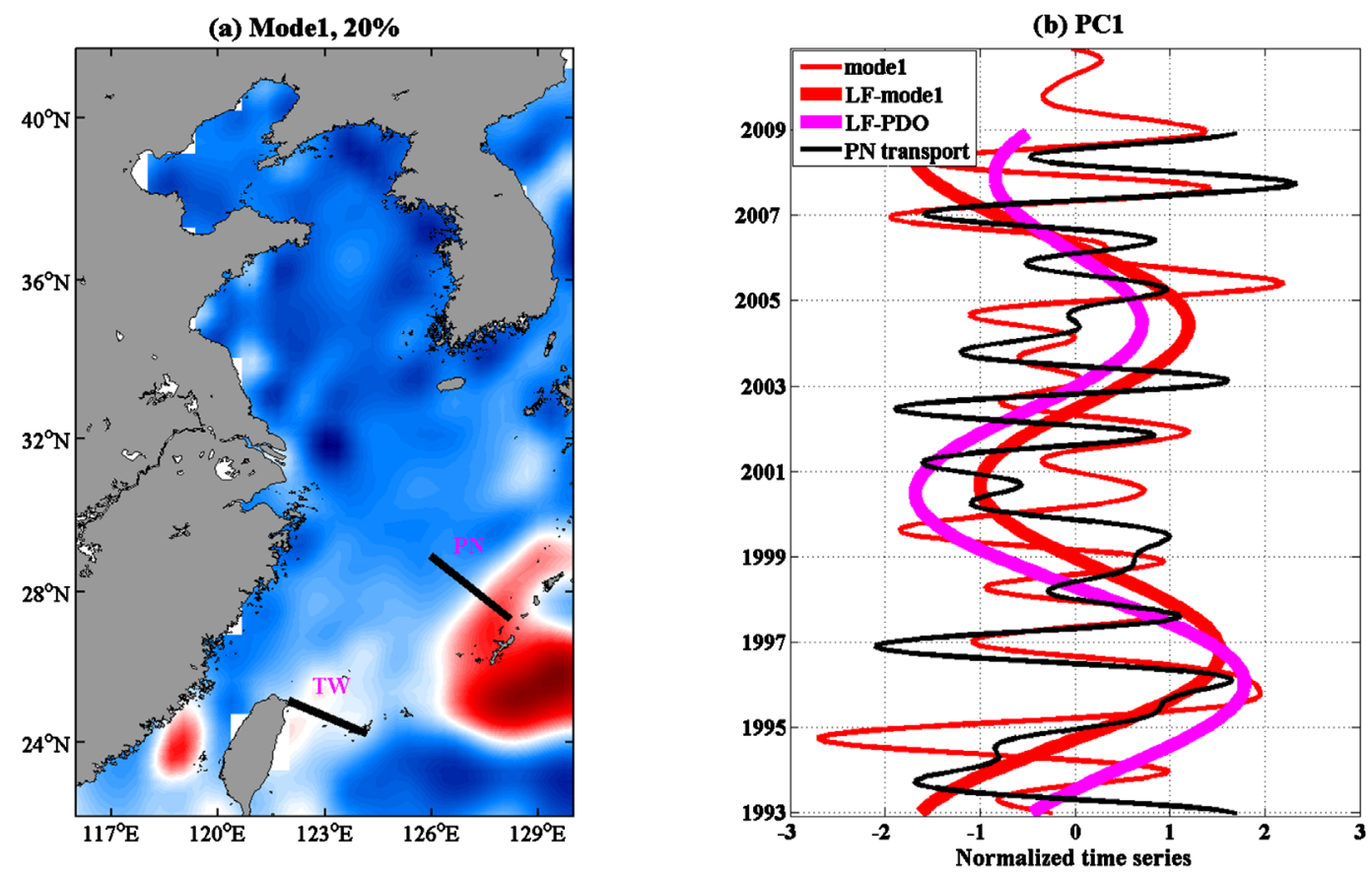

Figure 1. Empirical orthogonal function analysis of interannual sea level in the ECS: (a) First EOF. Two sections, TW and PN are plotted; (b) First principle component (PC1). LF-mode 1 represents the low-frequency PC1 based upon an 8-yr low-pass-filter while the LF-PDO represents the low frequency PDO time series. PN transport shows the interannual variation of the PN section transport based on a 13-month low-pass-filter.

way of measuring the fluctuation relationship between two time-series. To check the contribution rate of steric effect to sea level change, we use a point-wise hindcast skill $S$ to quantitative evaluate the forecast results. Skill function is given by

$$
S=1-\frac{\overline{\left(h_{0}-h_{\text {steric }}\right)^{2}}}{\overline{h_{0}^{2}}},
$$

where $h_{0}$ and $h_{\text {steric }}$ are observed and forecasted sea level anomalies respectively. High positive values of $S$ indicate $h_{0}$ and $h_{\text {steric }}$ have similar fluctuation variations and comparable magnitudes, while low values denote these two variables have large discrepancy of their magnitudes or the forecast results are inaccurate.

Before the analyses the liner trend of the sea level was removed by subtracting the annual average from each point to exclude the influence of global warming, and then a 13-month low-pass filter is applied to remove the seasonal variations. To study the modulation effect on the sea level of PDO, we apply an 8 years low-pass filter to extract the decadal signals of both variables. The Kuroshio mainly flows through the upper ocean above 1000 $\mathrm{m}$ depth [17], we choose the $1000 \mathrm{~m}$ depth as the reference-depth for the volume transport estimations.

\section{Results and Discussion}

\subsection{Interannual Sea Level Variation}

Sea level show obvious interannual variation in the ECS, but they vary geographically. For example, we divide the whole ECS into three regions by latitudes (every $5^{\circ}$ from $25^{\circ} \mathrm{N}$ to $40^{\circ} \mathrm{N}$ ), and then calculate their most significant periods by using the power spectrum method. For the southernmost region, periods of 14-month and 25 -month can be found. While for the middle region, the most significant period is 35-month and the second most significant period is 21-month, besides, the 14-month period is also significant. In contrast, the most significant period of the northernmost region is 21-month and the second most significant period is 35-month, while the third most significant period turns to be 15-month. For the whole region, the quasi-biennial period is dominant. To further study the interannual sea level variation in the ECS, two distinct modes are identified by 
applying the EOF method on the interannual sea level data. The first mode is characterized by a consistent change over the entire basin, accounting for $20 \%$ to the total variance (Figure 1(a)). The first principle component (PC1) shows significant interannual variability which superposes on the decadal fluctuation. Power spectrum analysis shows the energy of the PC1 peaks at 20-month and 27-month. Two features are identified from the PC1. First, the temporal change of this basin mode paces coherently with the interannual PN section transport, with the positively correlation coefficient reaching 0.39 at the $90 \%$ confidence level (Figure 1(b)). Correlation coefficient is even larger when we compare the TW section transport with the PC1, 0.43. Second, the temporal evolution is also characterized by decadal variation. Especially when the high frequency variability less than 8-yr are filtered, the low frequency PC1 shows high correlativity with the PDO index (decadal variation), 0.75 . Therefore, the first mode corresponds to the variability of the Kuroshio transport which is modulated by the PDO index on the decadal timescale.

The second mode accounts for $18 \%$ to the total variance, it shows opposite variability between regions interior of the Kuroshio path and the open seas exterior of the Kuroshio path (not shown). We find the PC2 is also modulated by the PDO $(\mathrm{r}=-0.66$, low-pass-filtered $(>8$ years $)$ ), but it shows non-significant relationship with the Kuroshio transport. We hypothesize that the second mode is the consequence of local oceanic and atmospheric adjustment. In the following paper, we will discuss the possible mechanisms of the interannual sea level variation from two aspects: large-scale atmosphere circulation effect and local oceanic and atmospheric adjustment.

\subsection{Large-Scale Atmospheric Circulation Effect}

Changes in interannual sea level variation are sensitive diagnostics of low-frequency nonlocal effects through atmospherictele-connections. Based on which, a number of studies have discussed the ocean's response to atmospheric forcing in the North Pacific. Qiu et al. [18] prove that low-frequency modulation of the Kuroshio Extension (KE) is due to wind stress anomaly in the eastern pacific. Andres et al. [19] indicate the sea level difference across the ECS-Kuroshio is modulated by ocean-basin scale wind stress forcing in the North Pacific through barotropic and baroclinic perspectives. Liu et al. [20] find a level response on the ECS is not consistent because of the climatological spatial features of wind in the North Pacific. All in all, through changing the Ross by wave and influencing the barotropic Sverdrup balance, large-scale wind effect over the North Pacific could affect sea level of the western coastal seas significantly.

Climatology wind stress curl and stress between 1960 and 2009 are shown in Figure 2(b). The zero curl anomalies contours lie at around $15^{\circ} \mathrm{N}$ and $45^{\circ} \mathrm{N}$, indicating the northward and southward transports of subpolar and subtropical gyres respectively. Negative wind stress curl between these two zero lines dominates most of the mid-latitude ocean. By contrast, positive wind stresscurl is restricted to the Aleutian chain and sub-polar ocean, as well as the subtropical ocean between $15^{\circ} \mathrm{N}$ and the equator. Negative wind stress curl over the mid-latitude ocean causes high sea level because of Ekman convergence in the upper layer, it contributes to the sea level variation of the ECS by Ekman transport and Ekman pumping effect. In order to assess their relationship, the correlation coefficient between zonal basin-wide mean wind stress curl and mean sea level of the ECS is calculated. Results show that the zonal averaged wind stress curl between $20^{\circ} \mathrm{N}$ and $45^{\circ} \mathrm{N}$ is negatively correlated with mean sea level of the ECS (at zero time-lag) at the 95\% confidence level on the interannual timescale (2 to 7 years). Although the correlation coefficients patterns are consistent, the values are related to the filter months we use. If a larger low-pass filter period is applied to both ECS sea level and the zonal averaged wind stress curl, their correlation coefficient is getting bigger. When we average the wind stress curl of the North Pacific Ocean between $20^{\circ} \mathrm{N}$ and $45^{\circ} \mathrm{N}$, and compare it with the mean sea level in the ECS, their correlation coefficient all exceed -0.4 from 1960 to 2009 no matter what filter techniques we choose on the interannual time scale (all the correlation values shown in the following text are statistical significant by t-test) (Figure 2(a)). It shows the remarkable large scale wind modulation effect on the western coastal seas. Due to the total different distributions of wind stress curl between the mid-latitude ocean and other regions, their correlation signs are different. Correlations at higher and lower latitudes are high positive, while in the mid-latitude, it's reversed.

To further study the baroclinic characteristics generated by wind stress curl anomalies in the mid-latitude ocean and sea level in the ECS, lead-lag method is used. It shows that when sea level lags the mean basin-wide wind stress curl anomalies 8 years on the interannual timescale (with a 5 years low-pass filter), their correlation is largest, -0.76 . Such result inosculates with the study of Andres et al. [19] which shows sea level difference 

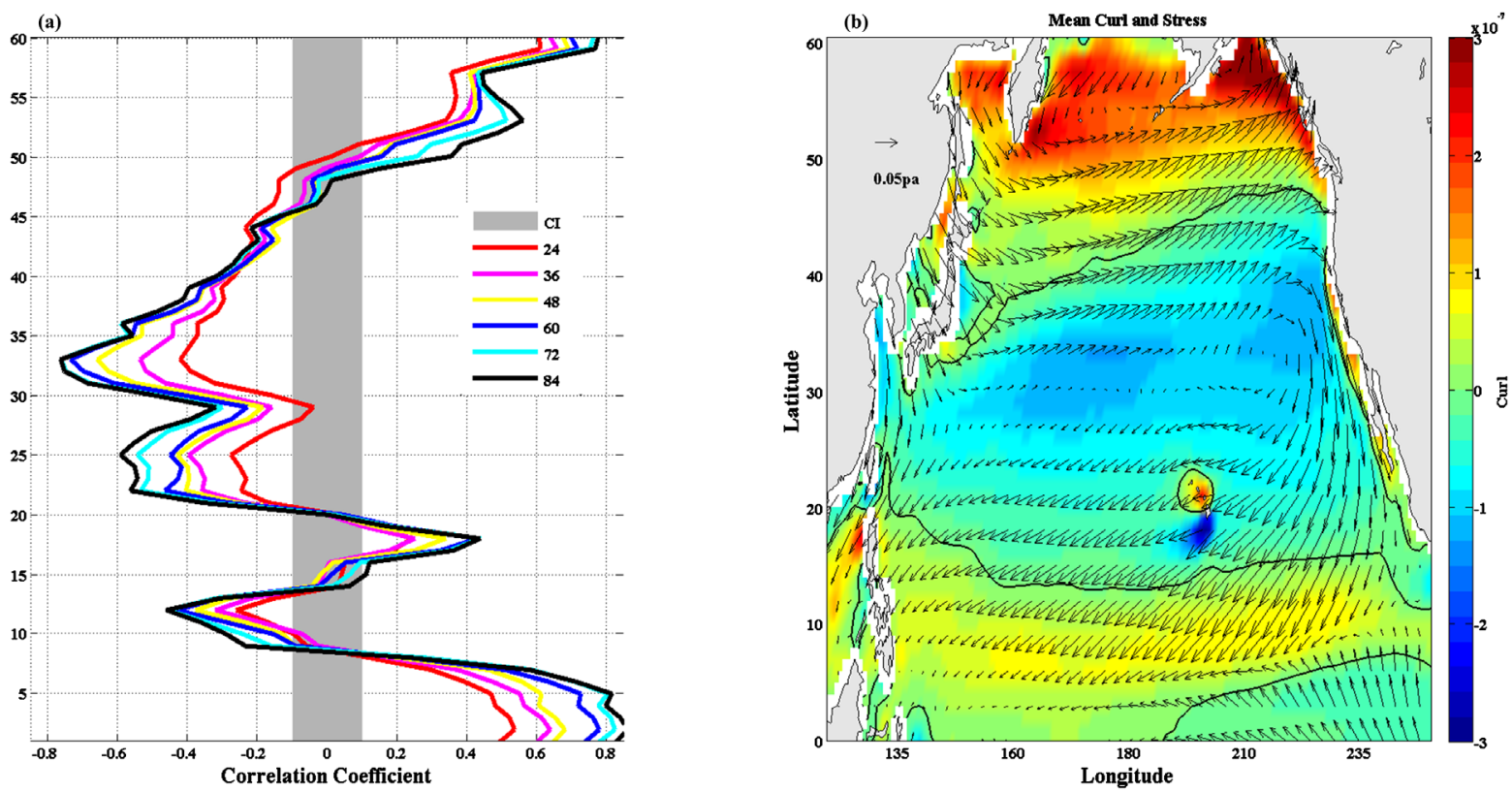

Figure 2. (a): Correlation between zonal averaged wind stress curl of the North Pacific and mean sea level in the ECS. Regions outside of the shaded area are significant at better than the $95 \%$ confidence level (CI). Solid lines with different colors show the correlation result based on low-pass filter of corresponding months (e.g. 48 means the high-frequency components less than 4-yr of these two time-series have been removed before calculating the correlation coefficient, and so forth); (b): Climatology wind stress curl (shaded) and wind stress of the North Pacific calculated between 1960 and 2009, black line denotes the zero isoline of wind stress curl (Units: $\mathrm{pa} / \mathrm{m}$ and $\mathrm{pa}$ ).

across the ECS-Kuroshio is negatively correlated with PDO at 7 year lag. The period, of which sea level lags wind stress curl anomalies, is consistent with a baroclinic mode. It also represents the time needed for subtropical gyre adjust the large-scale wind stress curl anomalies through baroclinic Rossby wave.

Furthermore, changes of the basin-wide wind field could affect the western boundary current by Sverdrup balance, then the changed Kuroshio transport could further effect the sea level by adjust the sea level gradient perpendicular to the current path. Previous studies have stated that the region from northeast part off the Taiwan Island to the PN section is important for water exchange between the ECS shelf and the Kuroshio. Considering the topography of the Kuroshio pathway, its shape resembles a deep trough. We treat the TW section as the entrance of the imagined trough, and PN section as the exit. The net transport between these two sections could measure the intensity of water intrusion into the ECS. The mean transport volume of the PN section is about 30 Sv of the study period, which is similar to the observed results [21] [22], indicating the transport is accurate and credible. We find the transport difference of these two sections have largest correlation coefficient with the mean sea level in the ECS, especially when sea level lags transport difference 2 months, 0.33 . This means that when the transport through the TW section exceeds the PN section, sea level in the ECS is relatively high, vice versa. It's reasonable to assume that increasing net influx could raise the sea level. It's evident that contribution of the Kuroshio could be approximately evaluated by the transport difference of these two sections. Therefore, we select all the months when transport difference larger than $15 \mathrm{~Sv}$ and less than $5 \mathrm{~Sv}$ respectively since 1993, and then the mean sea level in the ECS of corresponding months is calculated. Sea level corresponding to larger TD is larger than that with less TD, while the sea level difference is about $1.7 \mathrm{~cm}$. As the ECS is semi-closed and many passageways have been neglected, the $1.7 \mathrm{~cm}$ height difference couldn't completely show the contribution of the Kuroshio. However, considering the order of magnitudes of all inflow and outflow, the contribution does exist.

On the interannual timescale, when the transport difference advances the sea level 20 and 50 months, they have significant coefficients, 0.38 and 0.65 respectively (Figure 3(b)). When we extend the time series of TD to 1960, a decadal shift in the late 1970s could be obviously found. This decadal shift is similar with the wellknown atmosphere shift, indicating that atmosphere could affect the ECS sea level through changing the transport of the ECS-Kuroshio. Besides, the annually-averaged PN transport has high correlation coefficient, 0.65 , 

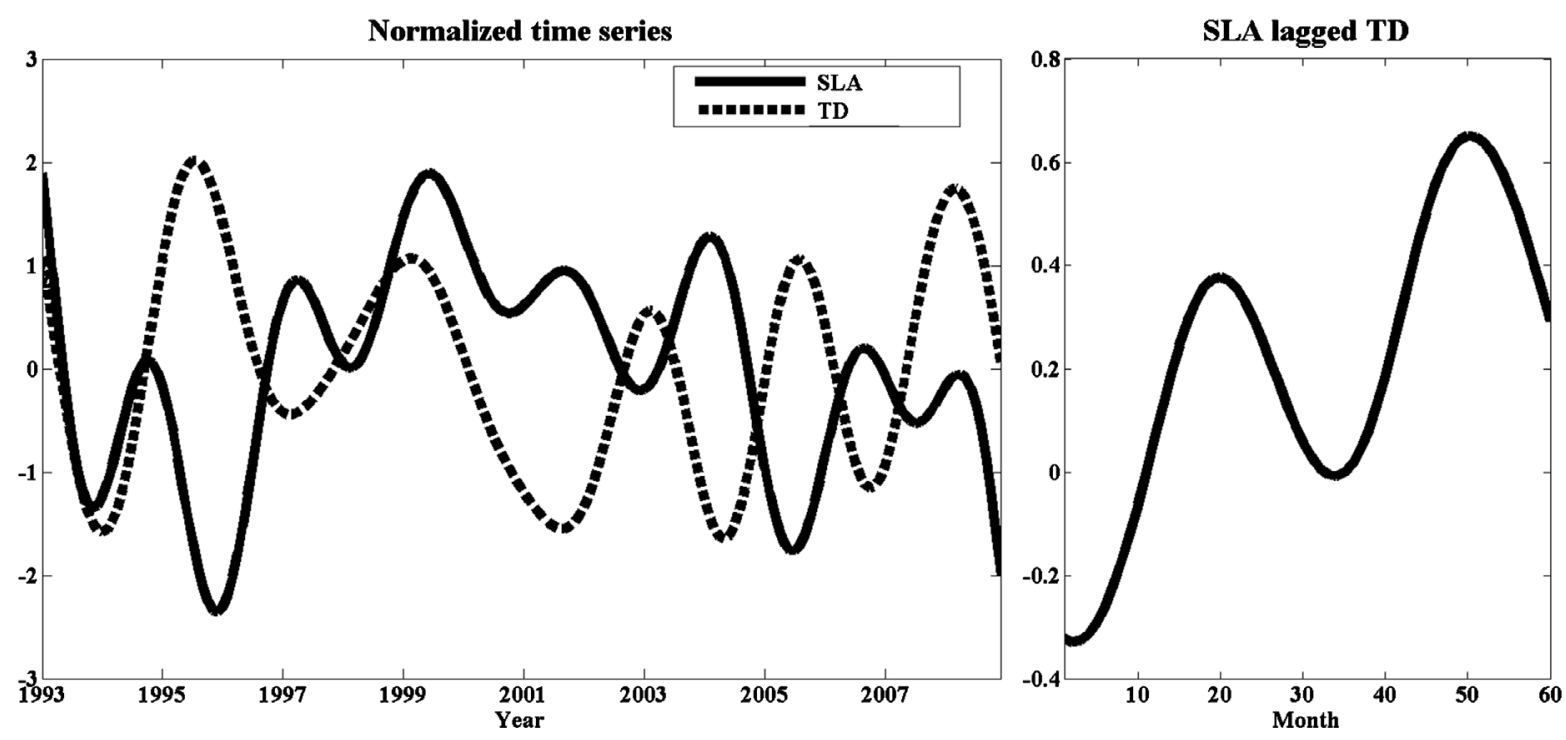

Figure 3. (a) Normalized time series of transport difference of two sections (TD) and the mean ECS sea level on the interannual timescale; (b) Correlations with different lag months between SLA and TD.

with the PDO index. Therefore, through changing the strength of the western boundary current, large-scale circulation of the North Pacific could also affect the ECS sea level indirectly.

\subsection{Local Oceanic and Atmospheric Adjustment}

Compared with the teleconnections of the large-scale atmospheric circulation effect, local oceanic and atmospheric effect is direct and also robust. Seeing from the climatology distribution of the wind stress curl anomalies in Figure 2(b), there is noclosed wind stress curl system above the ECS. Therefore, contribution of the Ekman pumping effect may be weak on the ECS sea level (see also in [23]). Local wind effect mainly reflects on squeezing and transporting water. Local zonal wind stress works directly on the sea surface, and causes the eustatic sea level. When zonal wind is negative (i.e. east wind stress component), onshore wind forces westward transport of the sea water. Sea water are stemmed by continent and accumulated towards the shore, which could lead to high sea level along the coast. Correlation method is also used here. We find the spatial averaged ECS sea level correlates well with the local zonal wind stress (same domain with the ECS). On the interannual timescale, local zonal wind stress has largest correlation with sea level when it advances sea level 3 months (exceed -0.6), while meridional wind stress shows insignificant correlation relationship.

Local oceanic adjustment process is also not ignorable. Knowledge of properties over the full water column is important for the interpretation of variability in sea level, heat storage and freshwater content, both at regional and global scales [24]. Based on which, steric sea level has been a key point in studying sea level variation in the past decades. Steric sea level is due to thermal expansion as the thermosteric component (TC) and haline contraction as the halosteric component (SC) first brought forward by [25]. Of which, thermal expansion contributes half to the global sea level rising during 1993 to 2003, others are from land-ice melting (Greenland ice caps and glacier melting), reported in the IPCC Fourth Assessment Report [2]. There is no doubt that steric effect is important to the sea level variation.

We remove the rising tendency of original data, steric sea level and SLA, to compare their fluctuation features. During the whole period, steric sea level shows significant seasonal characteristics, and it correlates positively high with SLA, 0.93. However, compared with the large seasonal amplitude, interannual steric sea level amplitude is much smaller, only accounting for a quarter of the original signals. Other features are revealed such as the interannual steric sea level doesn't show robust fluctuation as the SLA, though they correlate remarkable with each other $(r=0.6$, Figure 4). Besides, seeing from the error-bars of SLA and steric sea level, we can find that SLA also has larger seasonal fluctuation than the steric sea level. It indicates roughly that contribution of steric effect on the SLA is dominant on seasonal timescale, while on the interannual timescale, it's not.

To assess the relationship between $h_{\text {steric }}$ and sea level on the interannual timescale, their partial correlation 


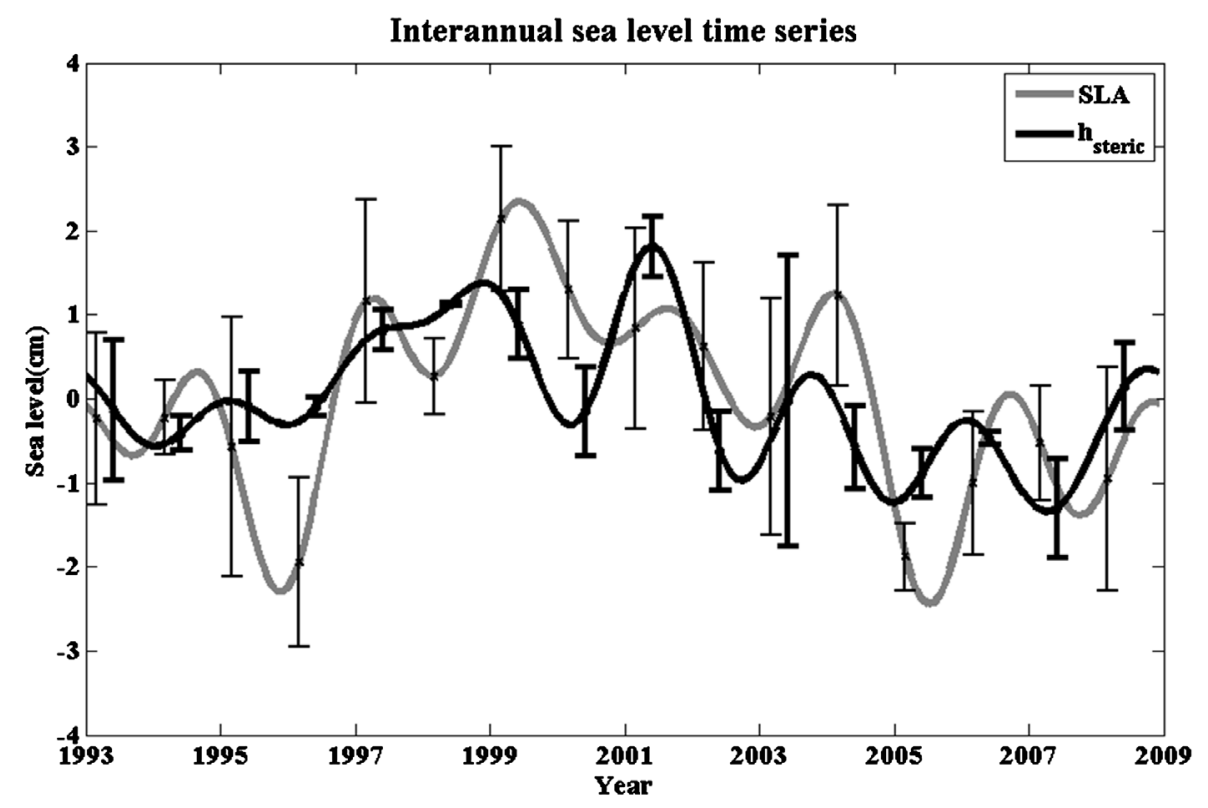

Figure 4. Interannual time series of $h_{\text {steric }}$ and sea level (Thin and thick error bars represent early standard deviation anomalies of $h_{\text {steric }}$ and SLA respectively, Units: $\mathrm{cm}$. For simplicity and easy distinguishing, each error bar of SLA locates at the beginning of the corresponding year while the error bar of steric sea level locates three months later.)

excluding effect of Kuroshio transport is calculated and shown on Figure 5 (left). For the usage of partial correlation analysis, it is aimed at finding correlation relationship between two variables after removing the effects of other variables. We can find that sea level induced by steric effect shows good correlation with SLA on the East Sea, especially on the northeast part $(r>0.8)$. Other largest correlation region locates on the open seas outside of the ECS-Kuroshio flow path. It's mainly because the water column there is deep enough to embody the contribution of steric effect. Contrary to which, it's insignificant or negative of most central part of the Yellow Sea. The primary reason may attribute to the existence of Huanghai Cold Water, which causes local reverse change of sea level on the interannual timescale. As for the coastal regions, the insignificant pattern is mainly because of the rivers inflow and anthropogenic factors, for the reason that water mass cycle accelerates and therefore the interannual characteristics are concealed. While the effect of eddy effect account for the insignificant correlation on the northeast part of Taiwan Island.

Figure 5 (right) shows the hindcast skill of Equation (1). The most obvious difference between the distribution of the scale $S$ and the correlation is in the ECS-Kuroshio basin. Large negative values of the ECS-Kuroshio basin demonstrate that $h_{\text {steric }}$ in this region is much larger than SLA, indicating that effect of the Kuroshio is more important. Largest values exhibit a northeast-southwest belt pattern from the Fujian and Zhejiang coast to the northeast part of the East Sea. The steric effect could explain $20 \%$ to $60 \%$ to the total interannual sea level variance gradually along the belt. Steric effect has little contribution to the Bohai Sea and the marginal areas of Yellow Sea, merely less than $10 \%$. Summing up, interannual steric sea level contributes significant from the Fujian and Zhejiang coast to the northeast part of the East Sea with contribution ranges from $20 \%$ to $60 \%$.

\section{Conclusions}

In this paper, interannual sea level variation and its possible mechanisms have been studied based on ocean and atmosphere reanalysis products. Sea levels show significant interannual variation in the ECS, and vary geographically and temporally. Two modes of 13-month filtered altimetry sea level data are identified by using EOF method and they can explain $20 \%$ and $18 \%$ respectively to the total sea level variance. The first mode corresponds to the variability of the Kuroshio transport which is modulated by the PDO on the decadal timescale. The second mode shows opposite variability between regions interior of the Kuroshio path and the open seas exterior of the Kuroshio path; it's a dipole mode. The second mode is also modulated by the PDO, but shows non-significant 

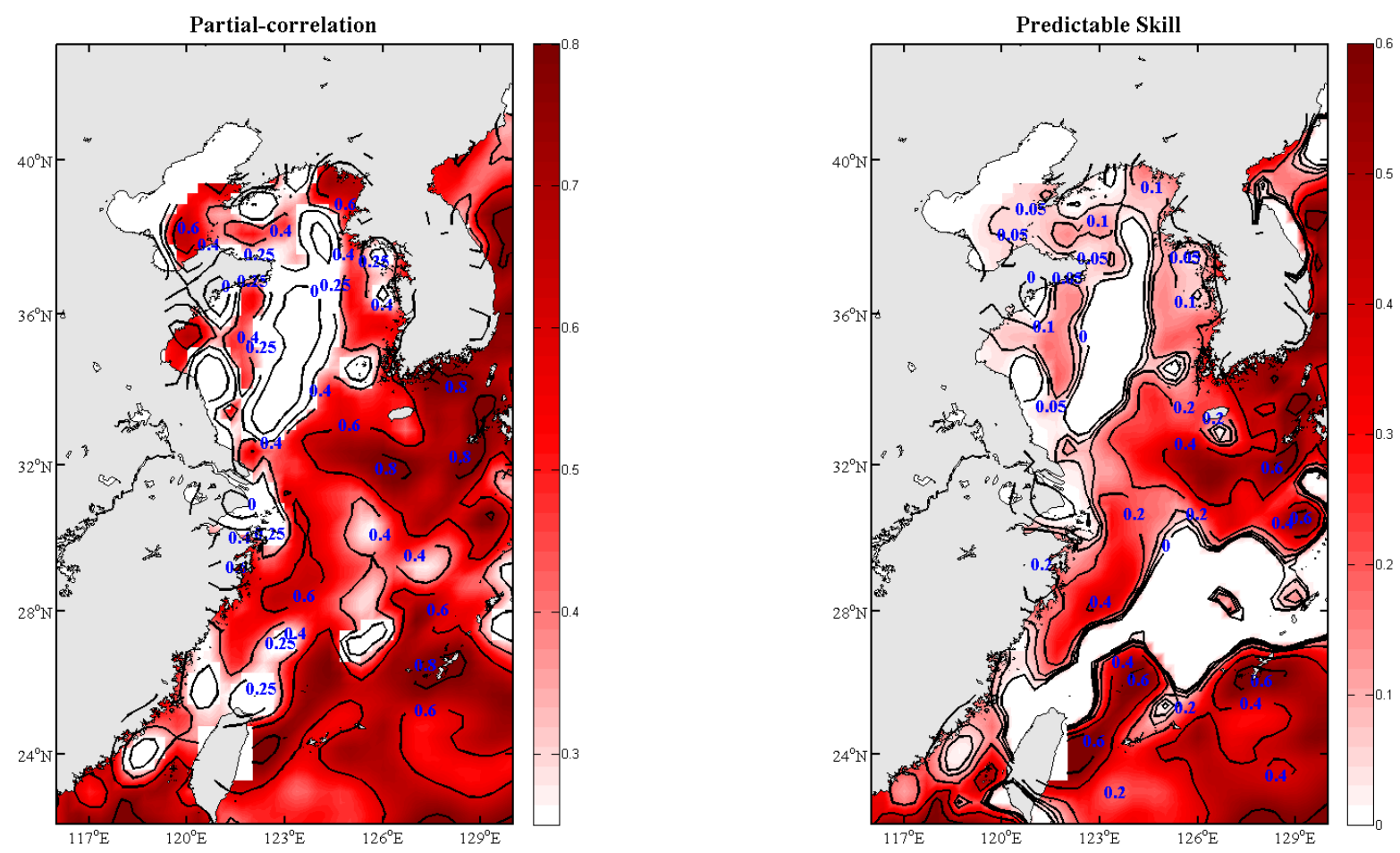

Figure 5. Left: Partial correlation between $h_{\text {steric }}$ and SLA (with a 24-month low pass filter) excluding effect of Kuroshio transport (Regions with correlation significant at the95\% level (i.e., where $r>0.25$ ) are shaded with significant positive correlations in red), interval: 0.1 . Right: Distribution of predictable Skill (\%) of $h_{\text {steric }}$ in accounting for the variance of SLA (Regions where $S$ beyond the absolute value of 1 are set to be vacant), interval: 0.1 .

relationship with the Kuroshio transport. It's hypothesized that the second mode is the result of the local oceanic and atmospheric adjustment.

Interannual sea level variation in the ECS is mainly forced by the low-frequency winds over the North Pacific. Mean sea level in the ECS is negatively correlated with the wind stress curl on the interannual timescale. The correlation coefficient is more than -0.4 at zero lag. This is consistent with a barotropic response to the largescale wind stress curl. Besides, westward propagating sea level anomalies signal which are driven by wind stress curl anomalies (centered between $20^{\circ} \mathrm{N}$ and $45^{\circ} \mathrm{N}$ ) could also influence the ECS sea level significantly. It shows that when sea level lags the mean basin-wide wind stress curl anomalies 8 years on the interannual timescale (with a 5 years low-pass filter), their correlation is the largest, -0.76 . The period, in which sea level lags wind stress curl anomalies, is consistent with a baroclinic mode. The lagging years are consistent with the timescale that the baroclinic Rossby waves propagate westward in the North Pacific Ocean. Annually-averaged Kuroshio transport has high correlation coefficient, 0.65, with PDO index. Moreover, if the transport difference has advanced sea level for 20 and 50 months, they have significant coefficients, with 0.38 and 0.65 respectively. Therefore, through changing the strength of the western boundary current, large-scale circulation of the North Pacific could also affect the ECS sea level indirectly (through sea level height adjustment).

Zonal wind stress is dominant in influencing the local interannual sea level. It correlates significantly with the local sea level, particularly when it has advanced sea level for 3 months, with a correlation exceeding -0.6 . For the contribution of local oceanic adjustment, a predictable skill analysis shows that interannual sea level can be slightly accounted for the steric effect, especially in areas with shallow topography. But it's noteworthy that steric effect contributes positively to the areas from Fujian and Zhejiang coast to the Korea/Tsushima strait that ranges from $20 \%$ to $60 \%$ gradually.

\section{Acknowledgements}

This study is supported by National Basic Research Program of China (973 program, Grant No. 2012CB417401 and 2014CB745004), NSFC project Nos. 41376008、 41176009 and 41106024, the Global Change and Air-Sea 
Interaction Project (GASI-03-01-01-09) and the Public science and technology research funds projects of ocean (201505013). The altimeter products are produced by Ssalto/Duacs and distributed by Aviso, with support from Cnes.

\section{References}

[1] IPCC (2013) Climate Change 2013: The Physical Science Basis. Contribution of Working Group I to the Fifth Assessment Report of the Intergovernmental Panel on Climate Change. In: Stocker, T.F., Qin, D., Plattner, G.-K., Tignor, M., Allen, S.K., Boschung, J., Nauels, A., Xia, Y., Bex, V. and Midgley, P.M., Eds., Cambridge University Press, Cambridge, 153. http://dx.doi.org/10.1017/CBO9781107415324

[2] IPCC (2007) Summary for Policymakers. In: Solomon, S., Qin, D., M. Manning. Chen, Marquis, M., Averyt, K.B., Tignor, M. and Miller, H.L., Eds., Climate Change 2007: The Physical Science Basis, Contribution of Working Group I to the Fourth Assessment Report of the Intergovernmental Panel on Climate Change Cambridge University Press, Cambridge.

[3] Cabanes, C., Huck, T. and de Verdière, A.C. (2006) Contributions of Wind Forcing and Surface Heating to Interannual Sea Level Variations in the Atlantic Ocean. Journal of Physical Oceanography, 36, 1739-1750. http://dx.doi.org/10.1175/JPO2935.1

[4] Cummins, P.F. and Lagerloef, G.S.E. (2004) Wind-Driven Interannual Variability over the Northeast Pacific Ocean. Deep Sea Research Part I: Oceanographic Research Papers, 51, 2105-2121.

[5] Timmermann, A., Shayne, M. and Jin, F.-F. (2010) Wind Effects on Past and Future Regional Sea Level Trends in the Southern Indo-Pacific. Journal of Climate, 23, 4429-4437.

[6] Landerer, F.W., Jungclaus, J.H. and Marotzke, J. (2007) Regional Dynamic and Steric Sea Level Change in Response to the IPCC-A1B Scenario. Journal of Physical Oceanography, 37, 296-312.

http://dx.doi.org/10.1175/JPO3013.1

[7] Li, J.C., Wang, Z.T. and Hu, J.G. (2000) Mean Sea Level Variation Using Historic Satellite Altimeter Data. Journal of Wuhan Technical University of Surveying and Mapping, 25, 343-347.

[8] Qiao, X. and Chen, G. (2008) A Preliminary Analysis on the China Sea Level Using 11 Years' TOPEX/Poseidon Altimeter Data. Marine Sciences, 32, 60-64.

[9] Yan, M., Zuo, J.-C., Du, L., et al. (2007) Sea Level Variation/Change and Steric Contributions in the East China Sea. International Society of Offshore and Polar Engineers, Lisbon, 2377-2382.

[10] Zhang, S.W., Du, L., Chang, Y.T. and Li, J. (2012) Interannual and Decadal Variation of Sea Level in the East China Sea. Proceedings of the 22nd International Offshore and Polar Engineering Conference (ISOPE2012), Greece, Rhodes, 17-22 June 2012, Vol. 3, 693-700.

[11] Wang, Y., Xu, H.Z. and Zhan, J.G. (2001) Complex Principal Component Analysis of Sea Level Variability over China Seas from Topex/Poseidon Altimetry. Acta Geodaetica et Cartographica Sinica, 30, 173-178.

[12] Han, G.Q. and Huang, W.G. (2008) Pacific Decadal Oscillation and Sea Level Variability in the Bohai, Yellow, and East China Seas. Journal of Physical Oceanography, 38, 2772-2783. http://dx.doi.org/10.1175/2008JPO3885.1

[13] Andres, M., Park, J.H., Wimbush, M., Zhu, X.H., Nakamura, H., Kim, K. and Chang, K.I. (2009) Manifestation of the Pacific Decadal Oscillation in the Kuroshio. Geophysical Research Letters, 36, L16602. http://dx.doi.org/10.1029/2009GL039216

[14] Liu, X.Y., Liu, Y.G., Guo, L., Rong, Z.R., Gu, Y.Z. and Liu, Y.H. (2010) Interannual Changes of Sea Level in the Two Regions of East China Sea and Different Responses to ENSO. Global and Planetary Change, 72, 215-226. http://dx.doi.org/10.1016/j.gloplacha.2010.04.009

[15] Balmaseda, M.A., Vidard, A. and Anderson, D.L.T. (2008) The ECMWF Ocean Analysis System ORA-S3. Monthly Weather Review, 136, 3018-3034. http://dx.doi.org/10.1175/2008MWR2433.1

[16] Ishii, M. and Kimoto, M. (2009) Reevaluation of Historical Ocean Heat Content Variations with Time-Varying XBT and MBT Depth Bias Corrections. Journal of Oceanography, 65, 287-299. http://dx.doi.org/10.1007/s10872-009-0027-7

[17] Book, J.W., Wimbush, M., Imawaki, S., Ichikawa, H., Uchida, H. and Kinoshita, H. (2002) Kuroshio Temporal and Spatial Variations South of Japan Determined from Inverted Echo Sounder Measurements. Journal of Geophysical Research, 107.

[18] Qiu, B. (2003) Kuroshio Extension Variability and Forcing of the Pacific Decadal Oscillations: Responses and Potential Feedback. Journal of Physical Oceanography, 33, 2465-2482. http://dx.doi.org/10.1175/2459.1

[19] Andres, M., Kwon, Y.O. and Yang, J.Y. (2011) Observations of the Kuroshio's Barotropic and Baroclinic Responses to Basin-Wide Wind Forcing. Journal of Geophysical Research, 116, C04011. 
http://dx.doi.org/10.1029/2010JC006863

[20] Liu, X.H., Lin, X.P., Wang, L.S. and Zhou, S.L. (2012) Pacific Wind Change and Its Influence on SST in East Asia Marginal Sea. Periodical of Ocean University of China, 42, 23-30.

[21] Ichikawa, H. and Chaen, M. (2000) Seasonal Variation of Heat and Freshwater Transports by the Kuroshio in the East China Sea. Journal of Marine Systems, 24, 119-129. http://dx.doi.org/10.1016/S0924-7963(99)00082-2

[22] Yuan, Y.C., Yang, C.H. and Wang, Z.G. (2006) Variability of the Kuroshio in the East China Sea and the Currents East of Ryukyu Islands, I: Variability of the Kuroshio in the East China Sea and the Meso-Scale Eddies near the Kuroshio in 2000. Acta Oceanologica Sinica, 28, 1-13.

[23] Zhang, Y.C., Zhang, L.F. and Wang, Y.G. (2010) Interannual Sea Level Variability in the North Pacific Ocean and Its Mechanisms. Chinese Journal of Geophysics, 53, 54-63. http://dx.doi.org/10.1002/cjg2.1472

[24] Ponte, R.M. (2012) An Assessment of Deep Steric Height Variability over the Global Ocean. Geophysical Research Letters, 39, L04601. http://dx.doi.org/10.1029/2011GL050681

[25] Tabata, S., Thomas, B. and Ramsden, D. (1986) Annual and Interannual Variability of Steric Sea Level along Line P in the Northeast Pacific Ocean. Journal of Physical Oceanography, 16, 1378-1398. http://dx.doi.org/10.1175/1520-0485(1986)016<1378:AAIVOS>2.0.CO;2 
Scientific Research Publishing (SCIRP) is one of the largest Open Access journal publishers. It is currently publishing more than 200 open access, online, peer-reviewed journals covering a wide range of academic disciplines. SCIRP serves the worldwide academic communities and contributes to the progress and application of science with its publication.

Other selected journals from SCIRP are listed as below. Submit your manuscript to us via either submit@scirp.org or Online Submission Portal.
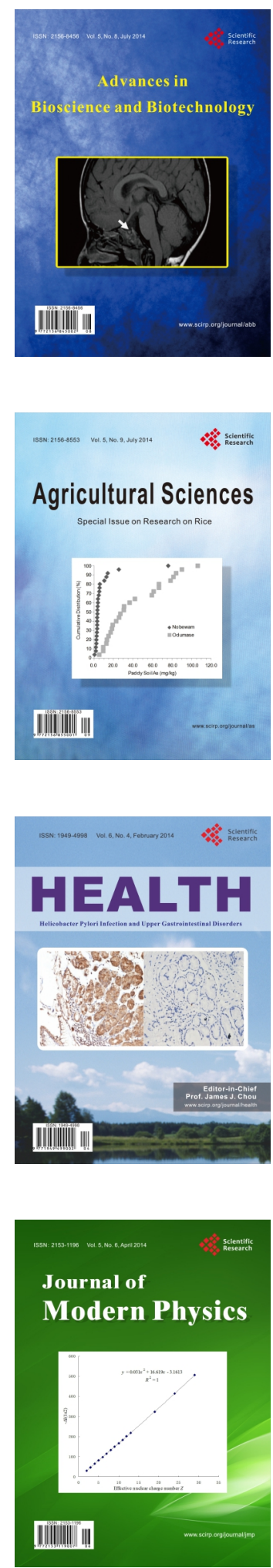
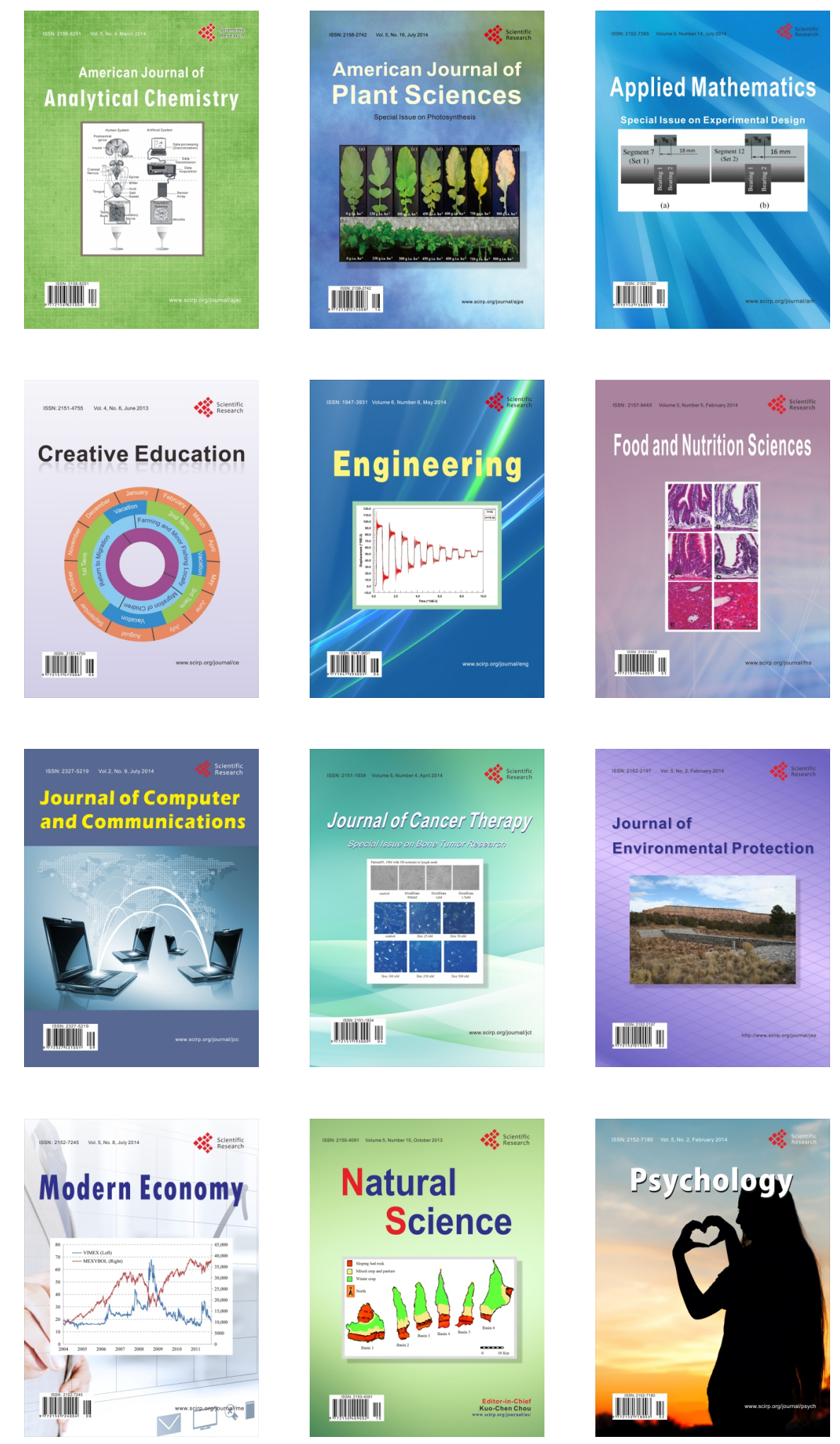